$12-22-2021$

"We, As Parents, Do Have a Voice": Learning From CommunityBased Programs Effectively Engaging Parents in Urban Communities

Elizabeth Gil

Ashley Johnson

Follow this and additional works at: https://research.library.fordham.edu/gse_facultypubs

Part of the Bilingual, Multilingual, and Multicultural Education Commons 


\title{
"We, as Parents, Do Have a Voice": Learning from Community-Based Programs Effectively Engaging Parents in Urban Communities
}

Urban Education

(C) The Author(s) 2021

Article reuse guidelines: sagepub.com/journals-permissions DOI: $10.1177 / 00420859211068466$ journals.sagepub.com/home/uex

(S)SAGE

\section{Elizabeth Gil' and Ashley Johnson ${ }^{2}$}

\begin{abstract}
Utilizing Yosso's community cultural wealth framework as a theoretical lens, we sought to examine how nontraditional, community-based family engagement programs impacted adult family members' thoughts and actions about engagement with their children's schools. The study drew primarily from the interviews, observations, and document analysis of two nontraditional family engagement programs in urban communities. Findings indicate that program approaches built upon and extended families' social and navigational capitals. Educational leaders can more meaningfully engage urban families by learning from and incorporating practices implemented by the programs we examine and discuss in this article.
\end{abstract}

\section{Keywords}

Urban Education, parent participation, community-based programs, community cultural wealth, social, cultural responsiveness, culturally

\footnotetext{
'Fordham University, New York, USA

${ }^{2}$ The Kresge Foundation, Troy, MI, USA

\section{Corresponding Author:}

Elizabeth Gil, Educational Leadership, Administration and Policy, Graduate School of Education, Fordham University, II 3 W 60th Street, Room II I9-D, New York, NY 10023, USA.

Email: egill@fordham.edu
} 
responsive family engagement, comparative case study, asset-orientation, subjects, case studies

\section{Introduction}

In the United States, there has been a national focus on the role that families play in their children's educational development (Henderson et al., 2007; Olivos, 2019). Researchers continue to find evidence that higher levels of involvement and engagement by parents are correlated with numerous positive child outcomes including increased academic performance, student motivation, and student attitude (Epstein, 2001). Parent involvement literature has also noted that white, middle-class families possess race, class, and cultural and social capital characteristics that reflect those valued most by American schools and are therefore more likely to be involved with their children's schools (De Carvalho, 2014; Ishimaru, 2014). Alternatively, parents with children attending schools in urban areas whose race, ethnicity, social class, and cultural norms often do not align as closely and are not as valued are often seen through a deficit lens as part of the problem, thus hindering effective at-school partnerships and collaborations (Ishimaru, 2014; Orr \& Rogers, 2010). However, when parents in urban communities are meaningfully engaged with schools, it enhances social capital and expands opportunities for students, their families, and neighborhoods (Auerbach, 2010).

Studies have documented that most at-school parent involvement activities are school-centered and generally restricted to a few types of activities and programs (Baquedano-López et al., 2013) which are established by the school and serve school-determined interests (Posey-Maddox \& Haley-Lock, 2020). These activities and programs often include parent-teacher conferences or ParentTeacher Associations and focus on parent volunteering or giving parents guidelines for assisting their children with academic development. Parents in urban communities tend to engage less frequently in these forms of involvement which can contribute to disparate schooling experiences and strained relationships between students, families, and schools (Lareau, 2001; Noguera, 2004).

Due to this home-school disconnect, researchers and educators have sought to uncover the conditions that support urban schools, families, and communities to form more productive relationships and partnerships that encourage student achievement (Khalifa, 2018). Alternative family engagement models that are not school-centered can encourage parents in urban communities to participate in their children's schooling (Bertrand \& Rodela, 2018; Delgado-Gaitan, 2001; Gil, 2017; Johnson, 2015). Yet, research has less frequently examined effective parent-centered family 
engagement programs which meaningfully engage and empower parents in urban communities to co-create and develop successful family-school relations. If increased family engagement and involvement are to be harnessed in urban communities, new models of family-centered engagement rather than school-centered involvement must be examined and implemented. Access to meaningful family engagement initiatives that recognize, and leverage families' existing strengths lead to empowerment (Gil, 2017; Johnson, 2015). Channeling these assets toward learning new knowledge and skills can aid in improving relationships with schools, resulting in better schoolfamily relationships and improved family engagement.

This comparative case study seeks to fill that gap in research by examining two nontraditional family engagement initiatives led by community programs. Both programs re-envisioned parent engagement, expanding beyond school-centered volunteering and academic involvement activities by focusing on family-centered approaches which empowered parents and community members in urban areas. We propose that educational leaders and schools can more meaningfully engage urban families by learning from and incorporating practices implemented in the community programs we examine and discuss in this article.

\section{Literature Review}

Family involvement and engagement practices in education encompass a wide range of philosophies, ideas, goals, and activities. Although there is no single form or method of family involvement, the conventional idea of parent involvement evokes images of families helping out in classrooms, managing fundraising activities, helping their children with homework, and serving on school leadership advisory boards. Many parents and families of all backgrounds are involved in supporting their children's education (Marchand et al., 2019; Posey-Maddox \& Haley-Lock, 2020), although their interpretations and behaviors may differ. For example, parental conceptions may include being involved generally in children's lives, teaching children respect for others, establishing relationships based on trust and communication, and providing children with advice on life (Auerbach, 2007; Posey-Maddox \& Haley-Lock, 2020).

Researchers have intentionally distinguished between family involvement, traditional school-initiated practices and activities, and family engagementmore expansive forms of parental participation in schools (Olivos, 2019). Family involvement is restrictive and often does not encompass the broader engagement roles and activities utilized by families with diverse backgrounds and in urban communities. Shirley (1997) defines parent engagement as 
"parents as citizens in the fullest sense...change agents who can transform urban schools and neighborhoods" (p. 73). In this article we acknowledge the delineation between "involvement" and "engagement." For the purposes of this article, we will utilize the term "family" to acknowledge the parents, guardians, grandparents, siblings, and close family members who are primary caretakers or who play a major role in children's lives. Utilizing "family" rather than "parent" reflects the importance of extended family relations within family structures (Baquedano-López et al., 2013; Flores et al., 2019).

\section{Urban Perceptions of Education and Family Involvement}

Parents' perceptions of schools are often influenced by their personal interactions with schools through their own prior experiences as students. In a study conducted by Davies (1993), the researcher found that parents reported several bad memories about schools and negative interactions and relationships with school personnel including teachers and administrators. These negative experiences influence the way parents in urban communities interact with their children's schools (Davies, 1993; Johnson, 2015).

Furthermore, McDermott and Rothenberg's (2000) study examined parents' perceptions of family involvement at a low-income, urban school where parent participants indicated that the school focused on representing the interests of "established white America and not the needs of low-income people of color" (p. 9). The parents whose children attended schools in urban areas perceived the school's approach as unwelcoming, resulting in painful encounters (McDermott \& Rothenberg, 2000). Due to these perceptions, parents "deliberately" withdrew from school involvement activities (McDermott \& Rothenberg, 2000, p. 9). This suggests that when interacting with urban schools, parents-particularly those of low-income-have to overcome both their personal negative experiences as students and their more recent negative interactions as parents.

These experiences have led many parents in urban communities to recognize a legacy of discrimination and mistrust that leads them to protect themselves and their children from indifferent, inadequate, or perceived racist school systems (Auerbach, 2007, 2010). These historically damaged relationships create additional barriers that further strain relationships between parents in urban communities and schools, and negatively impact these parents' at-school involvement (Khalifa, 2012). These relationship barriers, in addition to the lack of alignment in race, class, cultural and social capital characteristics and schools' overuse of school-centered parent initiatives, 
make it difficult for urban schools and parents in urban areas to form effective partnerships.

\section{Community-Based Approaches to Family Engagement}

Family engagement models that are not school-centered can encourage parents and other family members in urban communities to participate in their children's schooling (Delgado-Gaitan, 2001). Community-based programs may be sites where parents in urban communities meet outside of school initially to move toward solving a common issue or purpose (e.g., Jasis \& Ordoñez-Jasis, 2012). Community programs and schools that successfully engage families from diverse backgrounds exhibit three key practices: they focus on building trusting relationships among school staff, families, and community members; they recognize, validate, and support families' needs including class and cultural differences; and they broker and share power and responsibility between schools and families (Henderson et al., 2007). Urban community-based organizations (CBOs) highly effective in cultivating partnerships with families engaged families as a unit rather than interacting with family members as lone-standing individuals (Osterling \& Garza, 2004). These CBOs also provided varied opportunities for engagement, from providing emotional support to constituents to developing academic skills and training members to be advocates and leaders. The CBOs' agendas stemmed from members' expressed needs and interests, not pre-established goals or assumptions of community needs (Ishimaru et al., 2019a). Further, the community-based organizations were bilingually staffed by people representative of the demographics of the organization's constituents (Rusch et al., 2015). They also offered flexible schedules, accessibility to members, and collaborated with schools in the communities (Sanders, 2009).

CBOs often utilize a community organizing framework and focus on forming close relationships with constituents, through which they can support parents with multiple concerns. Organizing is a much different strategy than traditional parent involvement programs employ. Unlike many traditional involvement initiatives, organizing is based outside of schools and is often led, designed, and controlled by parents, community members, and community organizations (Warren \& Mapp, 2011). These programs also begin supporting parents in learning more effective engagement with their children's schools; for example, training parents and schools to engage "in a more equal dialogue" with all relevant stakeholders (Jasis \& Ordoñez-Jasis, 2004, p. 40). This emphasis on parent- and communitycentered relationships better position CBOs and organizations to effectively work within the complex circumstances often facing families from urban 
communities. These programs, then, can serve as resources from which schools can learn about effectively engaging families.

Through the emphasis on relationship building, organizing often increases and builds social capital, especially under circumstances where "financial capital" is scarce, as it can be in many under-resourced communities. The utilization of social capital can often provide a "critical resource" (Warren \& Mapp, 2011, p. 24). According to Coleman (1988), social capital are social structures that facilitate the actions of the actors leading to increased productivity. Persons or actors vary in the amount of social capital they have access to which influences their knowledge and understanding of the norms and social controls that govern systems or structures. Individuals with access to more social capital can accomplish much more than individuals who lack access to the same social capital (Coleman, 1988). Organizing builds and leverages bridging and bonding social capital. Bonding capital are social networks that are inward and between homogenous groups (Halpern, 2005). Bonding can be valuable for marginalized members of society to band together in social networks that support their collective needs (Putnam, 2000). Bridging capital are social networks composed of heterogeneous groups and provide opportunities to exchange information and ideas to build consensus among the groups representing diverse interests like parents from urban communities and school personnel in urban communities (Halpern, 2005; Putnam, 2000). Both forms of social capital have powerful positive social effects and can bond along some social dimensions and bridge across others at the same time (Putnam, 2000).

In many cases, community organizing strategies have been successful and have contributed to changes in policy, resources, personnel, school culture, and educational program improvements (Warren \& Mapp, 2011). Unfortunately, many schools and parent involvement programs are not built around principles of parental agency, leadership, and empowerment. Often programs and interventions are school-centered, do not consider the needs of families, and are generally restricted to a few types of activities and programs (Henderson et al., 2007). In contrast, family engagement programs created through community-based initiatives offer an alternative approach and an effective strategy to improve relationships and increase parent engagement partnerships among diverse families and schools.

\section{Theoretical Framework}

Community cultural wealth (CCW) brings to the forefront various forms of capital held by people from historically marginalized communities, who often reside in urban areas. We utilize Yosso (2005) theory of community 
cultural wealth to examine parents' participation in two community-based programs geared toward urban families. Yosso's (2005) theory provides an alternative to common interpretations of Bourdieu's (1977) notions of cultural capital. These common explanations focus on marginalized communities as lacking capital to explain the reproduction of social inequality. Instead, $\mathrm{CCW}$ capitals challenge deficit notions, serving "a larger purpose of struggle toward social and racial justice" (Yosso, 2005, p. 69) for historically underserved groups. The framework highlights assets that traditionally marginalized families possess and which their children bring into the schools they attend, but which often go unrecognized by those who adhere to narrow and traditional views of capital. These overlapping assets are aspirational, linguistic, familial, social, navigational, and resistant capital. These forms of capital work together to help communities maintain hope despite barriers, build on communication styles that transmit culture, leverage kinship ties, activate networks in order to navigate systems, and aid communities in resisting inequities.

Through applying CCW, we can identify how parents' engagement in the programs helped promote their strengths and re-envision their relationships with schools. As social and navigational capital particularly surfaced in our analysis, we focus on these. Here, social capital refers to social networks and community resources (Yosso, 2006). Navigational capital "refers to skills of maneuvering through social institutions" (Yosso, 2006, p. 44), which in this case, are the urban schools the children attend.

The CCW framework has been applied to examine families of color's experiences with their children's schools and how parents support their children's educational success. Recent research investigated how Black parents of children in predominantly white private schools navigated communication about their children's academic performance (Bolgatz et al., 2020). This study found that parents proactively communicated with school personnel to address issues and gain clarity about how to address their children's needs. These parents also depended on networks of other Black parents at the school for support. Another study documented the CCW capitals that Latino immigrant parents engaged to ensure their children's educational resolve (Guzmán et al., 2018). The researchers found that parents activated various forms of $\mathrm{CCW}$ capitals to gain resources for their children.

\section{Methods}

We investigate two nontraditional family engagement initiatives led by community programs engaging diverse families from an asset-oriented perspective. These programs fostered parents' existing strengths and expanded 
their views regarding engagement with their children's schools. The first case study examines a parent program that supported participants in how to identify and select high quality schools in a large urban K-12 school choice environment. The second case study, situated in a mid-sized urban city, examines a technology skills program mainly targeting Latino immigrant families, the aim of which was supporting parental connection to their children's schools, which were increasingly employing digitally-based communication platforms.

Our research questions draw on the experiences of the participants of the programs and we seek to better understand the following:

1. How does engagement in community-based programs foster the community cultural wealth of parents?

2. How do two community-based family engagement initiatives empower families from urban spaces to re-envision how they interact with their children's schools?

A comparative case study examines two or more cases and emphasizes comparison within and across contexts (Yin, 2003). The data for this qualitative comparative case study come from two larger case studies conducted individually by the researchers (Creswell, 1998; Stake, 1995). Our decision to combine these data was based on several factors. The studies shared the research interest of examining parents' experiences with community-based programs that were designed to enhance participants' connection and involvement with their children's schools. Both studies were conducted in Michigan in urban areas with large concentrations of traditionally underserved groups, with participants from similar demographics, and following similar research methods including prolonged engagement (Lincoln \& Guba, 1985) at the study sites via participant observation within the programs, interviews, and document analysis. Additionally, both programs were created in part by community organizers and utilized similar family engagement tactics such as relational approaches. Given these similarities, we decided to combine and re-analyze our data. By combining our data, we were able to have a more complete view of the experiences of study participants and how their participation in the community-based programs affected their relationships and involvement with their children's schools. We found much overlap in the participants' experiences with these community-based programs.

Although there is much overlap, there are also a few differences in the foci and purposes of the programs. Case 1 took place in Detroit, a large city, and examined the Community Reviewer Program (CRP, pseudonym), a novel family engagement program that sought to empower parents by training 
them to assess and evaluate the quality of schools by conducting citywide school visitations and evaluations. Case 2 took place in an unnamed midsized city and investigated Digital Home (DH, pseudonym), a program that taught technology skills with the intent of helping parents connect with their children's schools as local school districts increasingly engaged technology platforms to communicate with families. While the CRP took place at schools for the training and school visits, Digital Home's classes mainly took place within a local community center.

\section{The Community Reviewer Program (CRP)}

CRP was developed as part of the Detroit School Scorecard, a larger effort to increase school accountability and improve access to information about school quality to local parents and community members. The Scorecard assessed and compared all the city's schools against the same standard and rated them with letter grades from A to F. Most of the factors included in the original Scorecard were state mandated test scores. However, parents, community members, and school leaders called for additional measures to be utilized. In response, the CRP was created to include parent and community voices in the Scorecard (Johnson, 2015). A document from the program, about the program's background and purpose, stated:

The first Scorecard released was a top-to-bottom list of schools using just one data point: their average MEAP [Michigan Educational Assessment Program] or ACT scores. We got a lot of feedback from families and school staff that the quality of a school should be judged by more than one test...other factors also make up the quality of a school...it was important for community leaders to participate in the Scorecard process so they could get a better understanding of what it is all about and bring that understanding back to their schools, churches, and neighborhoods. (p. 3)

The CRP was a unique program model designed to meet specific needs requested by the Detroit community and sought to (1) provide access to other reliable information about school quality that parents could use to select the best school for their children and to hold schools accountable for their performance, and (2) generate and increase parent involvement at both the individual and community level (Johnson, 2015). At the individual level, the initiative wanted to provide families with tools and skills to make better informed school choice decisions. At the community-level, the CRP looked to develop a base of parents and community members who would make Detroit schools more responsive and accountable for their performance. 
The program sought to achieve this by providing parents with empowering information and experiences and by training community members to assess and evaluate the quality of at least three schools throughout the city.

\section{Digital Home (DH)}

In existence since 2011, Digital Home was founded and coordinated by a recently retired local principal who was concerned about the digital gap experienced by Latino immigrant families. The program's three overarching goals were: (1) teaching parents/guardians to gain basic computer skills to support their children's academic achievement, (2) connecting students to their parents/guardians, while promoting positive behavior and academics, and (3) motivating university students "through mentoring opportunities and understanding the importance of their role in serving the community." Most of DH's participants were local Spanish-speaking immigrant residents, though some U.S.-born and out-of-town people also took the basic technology skill classes. Adult family members were welcome to bring children to the technology lab, located in a community center, as well. DH appeared to offer the only technology classes in the area in Spanish. The program offered basic technology skills courses that met weekly for 10- to 12-weeks per course at no cost to participants, though donations were accepted. While the classes were initially targeted toward Latino immigrant parents, they were also open to community members who expressed interest in taking classes. Classes consisted of whole-group content presentations led by a bilingual volunteer instructor, and individual hands-on practice supported by bilingual Spanish-speaking volunteers called technology mentors. Within these sessions, there were also "little lessons" addressing topics such as how to interpret school report card codes and explaining and defining "grade point average."

Toward the end of each class, participants had time to reflect about their experience during the session and to share their thoughts with the group. Sessions ended with convivio, a time to share food and have informal conversation with one another. During this time, DH participants exchanged information about various concerns including housing and local schools. Every "generation" (cohort) of courses was commemorated with a clausura, a celebratory closing event. During each clausura, class participants shared their learned skills via PowerPoint presentations. Family members at the celebrations shared with other attendees the growth in confidence and technology usage on the part of their loved ones who had participated. Adult participants, their children, and volunteers received certificates of participation or of appreciation. (Table 1) 


\section{Data Collection}

Data collection for the CRP occurred between November 2013 and April 2014. Participants were recruited during program training sessions, and the final sample included eight parents including two fathers, five mothers, and one grandmother who was the legal guardian of her grandchild. The researcher conducted pre- and post- semi-structured interviews in participants' homes or at the local library. The two-hour pre-interviews were conducted after the program training, but before participation in the school visits; the two-hour post-interviews were conducted after each participant completed at least the three required school visits. The purpose of the pre-interviews was to gather life history and baseline details about participants' own experiences with schools and with their children's schools, as well as to learn about their beliefs about, and descriptions of, a good school. The post-interviews allowed participants to reconstruct the details of their experience with the program and encouraged parents to reflect on the meaning the experience held for them. The interviews were open-ended and

Table I. CRP and DH Program Contexts.

\begin{tabular}{|c|c|}
\hline Program and Setting & Purpose and format \\
\hline $\begin{array}{l}\text { Community Reviewer Program } \\
\text { Large, urban city in Michigan }\end{array}$ & $\begin{array}{l}\text { To empower parents to hold schools more } \\
\text { accountable and improve access to } \\
\text { information about school quality to better } \\
\text { inform school choice } \\
\text { Participants, mainly African American and Latinx } \\
\text { community members and parents of } \\
\text { school-aged children, completed training and } \\
\text { conducted three school evaluation visits. } \\
\text { Data gathered from the evaluations were } \\
\text { added to a Scorecard for each school }\end{array}$ \\
\hline $\begin{array}{l}\text { Digital Home } \\
\text { Predominantly Latinx area of a } \\
\text { mid-sized city in Michigan }\end{array}$ & $\begin{array}{l}\text { To teach parents/guardians with school-aged } \\
\text { children basic computer skills to support their } \\
\text { children's academic achievement and to } \\
\text { connect students to their parents/guardians } \\
\text { To help participants, most of whom were Latinx } \\
\text { immigrants, be able to access and understand } \\
\text { U.S. school systems } \\
\text { Weekly I.5-h classes in community center } \\
\text { computer lab, with lecture and hands-on } \\
\text { practice supported by volunteer instructors } \\
\text { and technology "mentors" }\end{array}$ \\
\hline
\end{tabular}


were structured like a conversation. The researcher utilized an interview guide with questions, but depending on how the interview evolved, sometimes deviated from the guide.

Data collection in DH took place from fall of 2015 to late spring of 2016, and interviews were conducted during April and May of 2016. The researcher, who had been a program volunteer since 2014, recruited participants in person during program activities as well as via Facebook, which participants had learned to use in DH classes. A long-time program volunteer posted recruitment information on social media and class members recruited parents via word-of-mouth. The researcher conducted 17 interviews with $18 \mathrm{DH}$ members: the program founder/coordinator, program volunteers, adult program participants, and children from adult participants' families. Interviews were conducted in English or in Spanish, depending on participant preference. In addition to interviews, the researcher had follow-up conversations with participants via direct messages on Facebook and in person.

This article focuses on data from interviews with adult DH participantsfour mothers, one father, and one grandmother. Interviews were conducted in various locations convenient to participants, including the computer lab, a participant's home, and a local cafe. All adult study participants had completed at least one DH course within the previous four years and one interviewee also continued as a volunteer. These conversational interviews also provided participants opportunities to highlight what they felt was important for others to know about DH.

For both studies the interviews provided insights into participants' experiences with schools, their definitions of parental involvement, the messages and skills learned during program participation, how their perceptions about ways of interacting with schools may have changed, and how participants applied their new knowledge to their children's schooling. Participants were informed that pseudonyms would be used in place of program and participant names, and that they could choose to stop participating at any time. In both studies, all interview participants signed consent forms and agreed to have interviews audio recorded. Although the data analyzed in each case was collected through semi-structured interviews conducted over a span of a month or two, each researcher spent between two and three years at each respective site. The second author observed CRP trainings, school site visits, and read all CRP documents and tools. The first author volunteered as a DH technology mentor for one-and-a-half years before the formal study period and several months afterward. This prolonged engagement (Lincoln \& Guba, 1985) allowed each researcher to become acquainted with and trusted within each study site. 


\section{Data Analysis}

We address the research questions of this study by synthesizing data initially collected independently for the two separate studies. Doyle (2003) argues that while cases are unique to the context and the participants' perspectives, comparing and synthesizing them can lead to new understandings and richness of the data. Thus, we saw it appropriate to reanalyze our data to explore in-depth how the community-based programs impacted parents' and other adult family members' orientations toward family engagement. Our goal was to better understand which activities and strategies utilized by the two nontraditional programs empowered the families and shifted their orientations about how they engaged with their children's schools. Given the research about how families and schools in urban environments struggle to create healthy relationships and partnerships, we sought to gain a deeper understanding of which environments and activities can help schools and families in urban communities overcome these barriers and re-envision and recreate their partnerships.

We conducted data analysis for the current study by rereading and re-coding interview transcripts, documents, and site observation notes. We first reread the interview transcripts, documents, and site notes. While rereading, we utilized axial coding where the study's theoretical framework of community cultural wealth's social and navigational capital served as primary codes for organizing the data (Patton, 2014). Our analysis focused on understanding what types of relationships and forms of new knowledge most supported and enabled our study participants to navigate their respective educational settings. Next, we compared the similarities and differences within and across the datasets. During the cross-case analysis phase, we utilized pattern matching and peer debriefing to identify our findings and themes (Creswell, 1998; Stake, 1995; Yin, 2003). Our rationale for merging our data sets was to increase the number of participants and the transferability of the findings as well as to provide a more complete picture of the experiences parents in urban communities have with community-based initiatives (Yin, 2003). The examples we highlight within this article are representative of what we observed and heard across participants throughout our studies and reflect the themes resulting from our combined analysis.

\section{Findings}

Both the Community Reviewer Program and Digital Home first acknowledged and later leveraged the assets that families possessed prior to their participation in the programs. These assets and capital included family members' individual capital gained through their lived experience with urban schools 
and the resilience that stems from having to navigate complex, inequitable social systems; the power of families' care for their children; and their sense of interdependence and reciprocity which led them to share their knowledge with others. These assets often go unrecognized in traditional school involvement programs and by those who adhere to narrow and traditional views of involvement and capital (Yosso, 2006).

Here, we focus our findings related to two forms of capital, social and navigational capital. For Yosso (2006), social capital engages "networks of people and community resources" (p. 45) through their peer groups. Connecting to these resources helps people to resist inequities faced by marginalized groups. Navigational capital facilitates people's ability to "make [one's] way through institutions not created with [traditionally marginalized communities] in mind" (Yosso, 2006, p. 43). While these forms of capital overlap and enhance each other rather than functioning discreetly, we discuss each in separate sections below.

\section{Social Capital}

Parents and students in urban communities possess social capital that is often not valued or recognized by educational institutions (Khalifa, 2010; Yosso, 2005). However, the community-based initiatives examined in this paper recognized and valued resources and existing social capital already possessed by these adult family members. The programs enacted approaches that led to participants' increased individual social capital through forming new relationships that created bonding, collective social capital that expanded their networks to better enable the family members to transcend the adversity they often faced alone when they interacted with educational institutions (Yosso, 2005).

New relationships leading to increased networks. In the Community Reviewer Program parents reported gaining social capital through new relationships and interactions with other parents and program staff. Tanesha, a mother of three children, described her experience of interacting with other program participants, particularly valuing the opportunity to meet parents from other schools. "It was cool to know that other parents share the same interest as you have." Tamika, another participant and single mother of two daughters spoke about her interactions with other parents and community members stating, "issues I was having with the schools a lot of other parents were having the same issues and [the program] allows us to figure out ways to come up with ideas and what we could talk to the schools [about] and get our needs met." Both mothers' comments illuminate the access to new 
relationships and parental networks the program provided, which was validating for them and many other participants. The new networks created a space where the participants felt less isolated and recognized that they had similar issues with schools that could be addressed as a collective rather than as individuals.

Digital Home served as a place of belonging and support. India, who grew up in an immigrant family from Ecuador and who was the mother of a fourth grader, found a "tight-knit community" where "there's just acceptance and love," which felt "like family." India felt accepted at DH, which "brought me out of my shell more." In DH she experienced a trusted community that shared information freely, rather than keeping it to themselves, a difference from what she had been accustomed to in other interactions. India shared, "it felt very liberating...to know that you have that support behind you." Though she still experienced moments of uncertainty, the DH community urged her to be more vocal and to support her daughter.

The social support present within Digital Home also helped participants to get involved in other local opportunities and connect outside of the program. One grandmother, Denisse, noted that the care she received in DH gave her the "patadita" (little kick) to pursue her longtime dream of attending college, enrolling in the community college, beginning with English classes. Along with pursuing her own educational dream, Denisse applied her language skills to translate for others who needed the help, which she noted was very expensive when people had to pay for the service. Her family members also remarked that after being in DH Denisse became more involved in the local community, where she had not done so in her decades living in the area.

Several DH participants attended parenting classes offered at the community center where DH classes took place. When class schedules conflicted, DH classmates and volunteers stressed the importance of the parenting sessions and shared class materials so others could catch up. Participants' increased familiarity with one another led to their support of one another on other occasions also. One DH volunteer talked about the importance of participants knowing one another and then, together, venturing into unknown territory. She recalled how two participants interested in learning English encouraged each other to attend and agreed to go together to the local campus. Neither had gone to college and both were unfamiliar with university settings. They would not have attended the classes alone. However, knowing another person who was interested and who was also unsure, they found strength in attending those classes together.

Developing individual and collective voice. Through relationships and expanded networks, the participants began to recognize their individual and collective 
"voices" as a community resource. Maria, who sent her son to the neighborhood public elementary school within walking distance of their home, discussed how participation in the program reminded her that she already had power and a "voice" in her son's education. She stated, "We, as parents, do have a voice, we have to have a voice for the children of today." Another parent participant from CRP's promotional video discussed how participation "woke her up" and gave her a "voice" and "power" in her child's education. She stated, "It's like something that had fell asleep in you woke up and you realized that your voice has power. And you realized that your voices together has [sic] even more power." Another parent in the CRP video stated,

If you keep grabbing these parents, you will have a voice. One parent should be able to grab the next parent, the next parent should be able to grab the next parent, and it should be a line of parents. Because we are the school system! We make the schools!

This newly formed collective of parents became known as the community reviewers who were "involved parents, residents, educators, and members of the business and nonprofit communities who want all of Detroit's children to receive an excellent education... who want to be a part of a longer-term movement to create great schools in Detroit." The new network of relationships produced social capital that participants could leverage as a community resource, due to the CRP's recognition of parent participants as assets and resources. Approaching family engagement from this lens, the CRP utilized the individual and collective capital to assess and evaluate urban schools.

Resulting from their participation in DH, several cohort members worked with the DH coordinator to present a workshop at a local community conference and prepared to co-facilitate DH class sessions they felt comfortable teaching to those in later cohorts. These were opportunities to come together and exercise leadership within their community. India witnessed how the larger Latino community in the area could unite, recounting a special screening of the movie "Cesar Chavez," which came to the area as a result of the local Latino community's efforts. India said, "to make it known, to the Spanish community...gave the community a different way of being more open...this was absolutely amazing. I'd never seen that many people in my life." This event was significant for India, who had never seen the local Latino community represented in such force in all her years living in the city. The movie screening served as an example of what the local Latino community could accomplish if they worked collectively.

It was through the interactions and relationships fostered in both community programs that participants increased their personal networks and 
recognized their individual and collective voice and social capital. The shared experiences of CRP and DH participants strengthened their sense of community belonging through the development of shared language and common experiences. Both programs recognized the power of parents' care for their children and their sense of interdependence and reciprocity. By first acknowledging the assets of each family member, the programs could then leverage them through the newly formed social networks to create a collective of experiences and voices related to schools and to the community in general. These new relationships and networks, at times, also resulted in vehicles that increased parents' navigational capital, as participants served as resources to one another.

\section{Navigational Capital}

Parents' participation in the Community Reviewer Program and in Digital Home also promoted members' navigational capital, which "acknowledges individual agency within institutional constraints" (Yosso, 2005, p. 80). For the participants in both programs, one constraint experienced in terms of relationships with children's schools related to not having information about how the school system functioned. Some parents, for example, did not know that they could have more direct interactions with school officials. The CRP and DH fostered participants' abilities to interact on more equal footing with stakeholders in their children's schools, in part by voicing their concerns. Participation in the programs also led to adult family members learning new skills and engaging with existing community resources they otherwise would not have known about. These programs helped equip parents with more knowledge about how to engage school personnel and establish the sense that their voices were important and should be heard to help direct their children's schooling experiences.

New knowledge toward confidence and self-efficacy in interactions with schools. The parents in the CRP experienced increased self-efficacy, new school navigational knowledge, and better understanding of their rights when interacting with schools. At the conclusion of the program, Maria felt more "confidence in interactions" with her son's school. She was more "willing to help in any way... help him with his education. And even in the school, like as a volunteer." At the time of the interviews, Maria was considering moving to another city, citing recent safety issues in her neighborhood. She disclosed that her experience in the CRP increased her confidence in interactions with school officials and educators when looking for a new school for her son. She stated, "I have to be able to ask questions, go in there and see how their 
setup is...now if I go in there, I know what my questions can be. And what I'm gonna be looking for." Maria's statements demonstrated that she increased her self-efficacy when interacting with schools as a result of participating in the program, leading to an increased ability to advocate for her son's education.

Several other parents also reported being more comfortable, confident, and knowledgeable about effectively navigating the broader school system. Hattie, who utilized school choice to send her granddaughter to a charter school, reported that participation in the program would influence her future methods for selecting a school for her granddaughter: "I will use some of the guidelines [from the program]. I'll be looking at the environment. I will be looking at teacher interactions. I'll be looking at diversity. I know I will be looking at safety, all of the things that are really important." Tamika considered how she viewed her children's schools prior to and after participation in the CRP. "In a lot of ways. I thought they were doing a fantastic job, but looking at what I saw [during the CRP] they can do a lot more, a lot better." Participation caused Tamika to reflect upon her prior school choice decision. She stated

I should have done more research. I shouldn't have took [sic] someone else's word for it. I shouldn't have been blind-sided by the newness [of her daughters' school] and when I saw constant turnover in teachers, I should have asked more questions then. Because now I see that it was something going on with the way they were operating her school.

In a hyper-school choice environment like Detroit, where parents had over 90 charter schools to choose from, it was very important that parents had the knowledge and confidence to navigate their very complex system of schools.

Similar to Tamika, Hattie, and Maria's experiences, participating in DH counteracted the negative message India had received as a middle schooler of "don't ask questions because then you're stupid." While India had always recognized her daughter Sierra's academic potential and consistently supported her learning, she was less personally involved with the school. Whereas DH class participants were urged to ask questions, India's own schooling had communicated that asking questions was undesirable. This lesson, learned years earlier, transitioned into India's reluctance to interact as a parent with school personnel. She never asked questions, instead having her mother-in-law ask them. With DH's emphasis that no question was stupid and being urged directly, "If you feel like something's not being done for you...you need to...fix it," India began asking questions and taking a more active role in school-related issues that arose, such as 
addressing her daughter's bullying. India experienced a transformation from seldom engaging with the school to wanting to know "about how everything goes, step by step by step." She compared herself before and after participating in $\mathrm{DH}$, as "more aware of my surroundings instead of being dead to the world and just drudging [sic] along." She remarked that school personnel noticed this change also: "I saw....an expression of shock, like "oh, you talk." India added, "I felt like I had a voice." She stated that she had witnessed a similar increase in confidence in her DH classmates. Like other parents in CRP and DH, this mother experienced a sense of agency resulting from a heightened awareness about the importance of being informed and asking questions on which she could act for her daughter's good. India's new orientation toward asking questions, something unthinkable prior to her DH participation, carried over into her professional life where asking questions was welcome and where "they love it." Unlearning the shame she had associated with asking questions allowed India to navigate Sierra's schooling better and had a positive effect on her own job prospects. With the positive messages she heard in $\mathrm{DH}$, exposure to resources, and the moral support she experienced, India grew in her ability to navigate her daughter's schooling experiences and Sierra also became highly involved in various after-school activities, including dance, horseback riding, and a girls' organization.

In DH, participants engaged in conversations related to school structures and norms and were encouraged to assert their right to be served. On different occasions, Maritza recounted how she had changed her children's academic programs. She noted that while she was prepared to hear "no" at first, she still advocated for programmatic changes when she felt that her children were not placed in challenging classes or when her daughter's class did not have a permanently assigned teacher. She described the different people she had to go through before being able to speak to a counselor to make changes. Her years of having children in the local school system, as well as conversations and contacts made in $\mathrm{DH}$, taught Maritza to better navigate her children's schools, figuratively and literally. She noted that being in $\mathrm{DH}$ provided an opening to resources and ideas that aided her ability to navigate her children's school system. As a result, she ensured that her children's school provided them with better educational opportunities.

Community peers as resources and navigational support. Other Digital Home parents also described how they began seeing one another not only as resources who helped each other in class, but also as navigational support and guidance. While helping one another with technology skills during class time, the adult participants also supported one another with different personal issues 
and shared information of interest within the community. Maritza spoke about how participants brought information to share during time set aside for announcements in each class session. In DH, participants pooled informational resources and connected one another to them; they became trusted resources for one another and formally recognized this sense of collective knowledge in their presentations at the end of program clausura. The increased social capital and recognition of collective capital referenced earlier, on occasion, also led to increased ability to navigate community and school institutions.

Luisa, a mother of two boys, also participated in various programs she learned about through DH. She participated in the parenting program that India and other families attended, explaining that the program was organized by a DH volunteer who was a graduate student at the local university. In addition to learning about the parenting program, Luisa became aware of programs happening in a nearby church and local English language classes. While Luisa knew some of her DH classmates prior to the technology classes, the program was a venue for meeting other parents from different countries and meeting university student program volunteers. Along with another parent she met in DH, Luisa brought school letters to the program coordinator for explanation or to confirm their understanding of the notices. In one instance, she and another mother learned about a local scholarship program and became knowledgeable about being able to add scholarship awards together to increase the financial accessibility of college for their children. DH volunteers, along with adult and children participants, also shared how they learned more about college through the interactions with the university volunteers. Luisa was able to help her children with school assignments and online communications and used her technology skills for her personal needs and interests, such as listening to music or to scripture on Sundays when she could not attend mass due to her work schedule. Luisa stated:

A lo mejor...para muchas...es...cualquier cosa, pero para los que no sabíamos nada...es bastante...de no saber ni de prender la computadora a ahora, a hacer cosas, y investigar cosas que a veces necesitamos./Maybe...for many... it's... [not a big deal], but for those of us who knew nothing [about using a computer]...it's a great deal...from not knowing even how to turn on the computer, and now do things, and investigate things that we sometimes need.

Learning to use a computer was powerful for Luisa to help her children and for herself. By participating in $\mathrm{DH}$, in addition to the connection with and support received from others, Luisa and other participants gained exposure to different community events and opportunities. Learning about local 
programs, such as parenting classes, or resources such as remote library services was useful for both their personal learning and promoting their children's learning.

The participants of both programs gained access to increased social and navigational capital that aided their ability to navigate relationships with school stakeholders and complex school systems and increased their selfefficacy. Participation in the community-based programs positively shifted participants' thoughts and actions about their own parental engagement and involvement. The programs facilitated family members' development of social and navigational capital, which in turn led them to feel more able to engage with their children's schools and within the community. By asking questions that leveraged their higher level of awareness of what was happening in the school and how schools functioned, and expecting engagement, family members elicited thoughtful answers from school personnel. The guardians' realizations and transformations resulted in their being able to make their children's schools more accountable to them.

Participants also noted a sense of belonging and community within their programs, where their shared experiences led to feeling supported and realizing the existing social capital and collective voice within their own communities. Participation in the programs provided access to navigational capital that increased Tanesha, Hattie, Tamika, Maria, India, Maritza, and Luisa's self-efficacy, school navigational knowledge, and understanding of their rights when interacting with schools. The programs provided parents critical new information, new networks, and new skills which supported them to better navigate the schools in their respective cities.

\section{Discussion}

The goal of this study was to better understand what activities and strategies two nontraditional programs utilized to empower participant families and shift their orientations about how they engage with their children's schools. While the Community Reviewer Program and Digital Home were community-based programs created outside of schools, there are transferable lessons that schools can learn and utilize from these programs to help them better engage families from urban communities. First, both programs took a bottom-up approach (Alameda-Lawson \& Lawson, 2019), recognizing and acknowledging assets and community cultural wealth that families already possessed and gained through their lived experiences. Therefore, they viewed parents from an asset orientation as co-constructors and agents in their children's education, rather than problems to solve (Warren \& Mapp, 2011). Through this lens, the programs co-constructed initiatives to meet 
families' specific contextual and cultural needs and desires (Alameda-Lawson \& Lawson, 2019) and intentionally co-created spaces to leverage and increase social and navigational capital the parents already possessed, fostering greater inclusion of traditionally marginalized parents in schools.

School leadership plays a crucial role in how schools engage parents. School leaders have the ability to design and implement policies and shape the norms and expectations for how their schools will engage parents (Marschall \& Shah, 2020). Educational leaders can more meaningfully engage families who reside in urban settings by learning from and incorporating the practices implemented in the CRP and DH. While both initial studies ended several years ago, the issues addressed are still relevant. Most parent involvement programs remain school-centered (Posey-Maddox \& Haley-Lock, 2020) and do not acknowledge assets and community cultural wealth. Furthermore, traditional involvement approaches rarely provide opportunities for parents to share power and co-create the programs, do not respond to families' contexts, and do not intentionally create space for parents in urban communities to access social and navigational capital through peer-to-peer relationships. When school leaders design involvement and engagement programs to better engage with parents in urban communities, they should utilize $\mathrm{CCW}$ as a lens to resist deficit perceptions and notions of their students' families. CCW (Yosso, 2005) brings to the forefront various forms of capital already held by people from historically marginalized communities. Applying a CCW lens would aid in acknowledging the multiple assets and capital possessed by students' families, and then working with families to co-create engagement experiences that build upon families' cultural wealth and meet their specific needs and desires. Both the CRP and DH functioned from the perspective that parents were "bearers of knowledge" (Baquedano-López et al., 2013, p. 154), with their own understandings, which could be applied to their children's schooling. Parents bring with them assets that often go unrecognized by urban schools. Schools should shift from deficit-orientations and rather, interact with parents through an asset-oriented lens. This should be the foundation for all school and family interactions.

Because the programs acknowledged and valued parents' roles within their children's education, each program listened to, learned from, and provided space for parents to co-construct the programs to deliberately meet families' needs and respond to participants' priorities (Alameda-Lawson \& Lawson, 2019; Ishimaru et al., 2019b). Co-creation and ownership are essential components of programs wishing to bridge the divide between community and governance and cause culture shifts, such as improving parent engagement in urban schools (González, 2019). In the CRP, family members worked as 
partners in developing the assessment tools utilized during their school visit evaluations. In DH, the curriculum was adapted to be responsive to what participants wanted to learn, and how they wanted to learn and apply their learning. Parents also, on occasion, planned for and led learning experiences as well. Both programs viewed parents as active agents whose knowledge could benefit the quality of the programs, other parents, their children, schools, and the community as a whole. This more holistic and place-based approach (Green \& Gooden, 2014) led to interacting with parents as partners who should be heard and thoughtfully engaged in a contextually-based way. By acknowledging that "Every family has something to contribute to the school" (Henderson et al., 2007, p. 140), schools can work with parents for the benefit of their children, the school, and the community-at-large. As school leaders gain a greater understanding of families' contexts, including strengths and needs by working closely with them and encouraging and supporting families' own advocacy, urban school leaders themselves can address multiple issues faced by those they serve and become better advocates (Green $\&$ Gooden, 2014). A place-based approach and co-construction with families is a policy change that should be implemented by all school leaders when designing family engagement initiatives. Families should be a part of the process of developing initiatives, from design through implementation.

As participants in the CRP and DH engaged in peer-to-peer program activities, family members began seeing their individual experiences were not theirs alone but also shared with others in the programs. Peer-to-peer connections among the parents in the programs were powerful and impacted how parents interacted with their children's schools, made decisions, and even engaged within their communities. Recognition of shared circumstances led them to view themselves as part of a larger whole with a collective voice, increasing bonding capital within their respective communities (Alameda-Lawson \& Lawson, 2019; Warren \& Mapp, 2011). Both programs opened spaces for dialogue, leading parents to "activate their strengths and know-how for individual and collective purposes" (Alameda-Lawson \& Lawson, 2019, p. 1101). As they came together to address common issues through the programs, those in the CRP created a scorecard that was reflective of their values. During DH sessions participants problem solved issues ranging from housing to immigration to interactions with their children's schools. As parents recognized these shared experiences and supported one another to problem solve and address multifaceted issues, they encouraged one another to act on their care for their children and engage their sense of reciprocity which led families to share their knowledge with others.

These shared voices and experiences in some cases led to stronger social networks and to a sense of kinship within the program settings. Lane and 
Id-Deen (2020) refer to these kin-like relationships as "program families" (p. 16) that support participants' aspirations and foster their collective wellbeing and motivation. The programs served as relationship-building centers leading to the establishment of peer-to-peer support of individuals as well as provided collective strength to engage with school officials where parents had previously felt silenced and isolated. These new "program families" made participants feel less isolated and more confident about their experiences and knowledge. Through engaging with one another, parents found strength in their efforts to navigate relationships with their school personnel (Bolgatz et al., 2020; Delgado-Gaitan, 2001; Ishimaru, 2014), offered one another advice, and served as buffers when issues arose.

Multiple parents in both programs discussed how, through their participation, they came to recognize that they were not alone and knew what questions to ask to better inform their decision-making. The relationships formed, along with other advocacy, led to increased structural social capital in the form of access to and interchange of information, and fostered parental capacity to speak out in schools regarding their children's needs (Ishimaru, 2014). Fellow participants and others within the programs encouraged families to act in order to have their concerns addressed, making them more apt to vocally advocate for their children and resist marginalization stemming from deficit notions about parents (Dyrness, 2007). Parents like Maria and India became more likely to initiate contact with their children's teachers to address issues such as bullying. Many parents went from not knowing they could have direct interactions with school officials and not asking questions to knowing different questions they would pose to school officials in the future. As families in the programs learned together, they expanded their knowledge of what they should be aware of, including teacher turnover, the importance of teacher-student interactions, students' academic programs, and asking a variety of questions. This new knowledge about how to engage school personnel created more equal footing with their children's schools. In these ways, parents and guardians held their children's schools more accountable. School leaders must provide multiple platforms for families to engage with schools, but also to dialogue with one another.

As the two programs illustrate, rather than adhere to deficit-based perspectives that assume that parents are problems or that focus on directing agendas, the CRP and DH emphasized the importance of authentic, power-sharing parent engagement within their respective community settings. Unfortunately, traditional involvement approaches rarely provide opportunities for bottom-up approaches that power-share and co-create programs with families, do not respond to families' place-based contexts, and do not create space for urban families to gain 
access to social and navigational capital through peer-to-peer interactions and relationships.

\section{Conclusion}

This study aimed to learn about how parents' experiences in the Community Reviewer Program and in Digital Home, two urban asset-based communitycentered programs, contributed to their conceptions of and actions toward engagement with their children's schools. By providing an in-depth example of community-centered parent engagement, this work expands the concept and interpretations of family involvement, engagement, and empowerment by looking beyond formal at-school settings as the only method for engaging families. The programs, which took holistic, place-based, and contextually-centered approaches, were spaces for dialogue among parent participants, leading to greater connection among parents and increased parent engagement in their children's schools and within their local communities. Schools and school leaders can learn from the community-based programs described in this article. As these cases illustrate, engaging parents can take varied forms. Enacting relational approaches can result in a sense of individual and collective empowerment which encourages parents to engage more with schools. Centering parental engagement initiatives within communities may also facilitate initiatives' abilities to be responsive to parents' needs while also emphasizing families' agency and bringing their assets to the table. Additionally, these initiatives are aligned with urban parent perceptions of education, which are holistic, rather than solely academic and school-centered.

Through participation in the CRP and in DH, parents gained social capital with new networks of parent peers and realized that they had more power than they initially believed. The new relationships and networks gained gave parents a greater sense of belonging and empowered them to recognize their collective power and communal voice were valuable resources. The Community Review Program and Digital Home staff and volunteers were successful because they acknowledged and engaged parents from the perspective that they were valued and had capital to contribute to improve their children's educational experiences. After acknowledging families' assets, schools should intentionally create spaces that encourage parents to build stronger relationships with one another. As demonstrated in the programs examined in this article, collective support among parents can enhance and help parents develop the confidence and knowledge to re-envision traditional involvement experiences and transform their relationships with schools. If school leaders are to effectively engage historically marginalized parents in 
urban communities, they must begin by engaging families from an asset orientation rather than a deficit one.

\section{Declaration of Conflicting Interests}

The author(s) declared no potential conflicts of interest with respect to the research, authorship, and/or publication of this article.

\section{Funding}

The author(s) received no financial support for the research, authorship, and/or publication of this article.

\section{ORCID iD}

Elizabeth Gil (iD) https://orcid.org/0000-0002-5308-6931

\section{References}

Alameda-Lawson, T., \& Lawson, M. A. (2019). Ecologies of collective parent engagement in urban education. Urban Education, 54(8), 1085-1120. https://doi.org/10. $1177 / 0042085916636654$

Auerbach, S. (2007). From moral supporters to struggling advocates: Reconceptualizing parent roles in education through the experience of workingclass families of color. Urban Education, 42(3), 250-283. https://doi.org/10. 1177/0042085907300433

Auerbach, S. (2010). Beyond coffee with the principal: Toward leadership for authentic school-family partnerships. Journal of School Leadership, 20(6), 728-757. https://oi.org/10.1177/105268461002000603

Baquedano-López, P., Alexander, R. A., \& Hernández, S. J. (2013). Equity issues in parental and community involvement in schools: What teacher educators need to know. Review of Research in Education, 37(1), 149-182. https://doi.org/10.3102/ $0091732 X 12459718$

Bertrand, M., \& Rodela, K. C. (2018). A framework for rethinking educational leadership in the margins: Implications for social justice leadership preparation. Journal of Research on Leadership Education, 13(1), 10-37. https://oi.org/10. $1177 / 1942775117739414$

Bolgatz, J., Crowley, R., \& Figueroa, E. (2020). Countering white dominance in an independent elementary school: Black parents Use community cultural wealth to navigate "private school speak". The Journal of Negro Education, 89(3), 312-327. https://doi.org/10.1177/0042085920914378

Bourdieu, P. (1977). Outline of a theory of practice (Vol. 16). Cambridge University Press.

Coleman, J. S. (1988). Social capital in the creation of human capital. American Journal of Sociology, 94, S95-S120. https://doi.org/10.1086/228943 
Creswell, J. (1998). Qualitative inquiry and research design: Choosing among five traditions. Sage.

Davies, D. (1993). Benefits and barriers to parent involvement: From Portugal to Boston to Liverpool. In N. F. Chavkin (Ed.), Families and schools in a pluralistic society (205-216). State University of New York Press.

De Carvalho, M. E. (2014). Rethinking family-school relations: A critique of parental involvement in schooling. Routledge.

Delgado-Gaitan, C. (2001). The power of community: Mobilizing for family and schooling. Rowman \& Littlefield Publishers.

Doyle, L. H. (2003). Synthesis through meta-ethnography: Paradoxes, enhancements, and possibilities. Qualitative Research, 3(3), 321-344. https://doi.org/10.1177/ 1468794103033003

Dyrness, A. (2007). 'Confianza is where I can be myself': Latina mothers' constructions of community in education reform. Ethnography and Education, 2(2), 257-271. https://doi.org/10.1080/17457820701350848

Epstein, J. L. (2001). School, family, and community partnerships: Preparing educators and improving schools. Westview Press.

Flores, R. Q., Morgan, P., Rivera, L., \& Clark, C. (2019). Latinx family engagement in schools and surrounding communities: Assessing the impact of parent (and other family member) development on improving student educational outcomes at gene ward elementary school. Education Sciences, 9(2), 149. https://doi.org/10.3390/ educsci9020149

Gil, E. (2017). Engaging the community cultural wealth of Latino immigrant families in a community-based program (Publication No. 10622139) [Doctoral dissertation, Michigan State University]. ProQuest Dissertations \& Theses Global.

González, R. (2019). The Spectrum of community engagement to ownership. Movement Strategy Center.

Green, T. L., \& Gooden, M. A. (2014). Transforming out-of-school challenges into opportunities: Community schools reform in the urban midwest. Urban Education, 49(8), 930-954. https://doi.org/10.1177/0042085914557643

Guzmán, B. L., Kouyoumdjian, C., Medrano, J. A., \& Bernal, I. (2018). Community cultural wealth and immigrant latino parents. Journal of Latinos and Education, 20(1), 78-92. https://DOI: 10.1080/15348431.2018.1541801

Halpern, D. (2005). Social capital. Polity Press.

Henderson, A. T., Mapp, K. L., Johnson, V. R., \& Davies, D. (2007). Beyond the bake sale: The essential guide to family-school partnerships. The New Press.

Ishimaru, A. M. (2014). When new relationships meet old narratives: The journey towards improving parent-school relations in a district-community organizing collaboration. Teachers College Record, 116(2), 1-49. https://doi.org/10.1177/ 016146811411600206

Ishimaru, A. M., Bang, M., Valladares, M. R., Nolan, C. M., Tavares, H., Rajendran, A., \& Chang, K. (2019a). Recasting families and communities as co-designers of education in tumultuous times. Boulder, CO: National Education Policy Center. Retrieved [August 28, 2019] from http://nepc.colorado.edu/publication/familyleadership. 
Ishimaru, A. M., Lott, J., Torres, K. E., \& O'Reilly-Diaz, K. (2019b). Families in the driver's seat: Catalyzing familial transformative agency for equitable collaboration. Teachers College Record, 121(11), 1-39. https://doi.org/10.1177/016146811 912101108

Jasis, P., \& Ordoñez-Jasis, R. (2004). Convivencia to empowerment: Latino parent organizing at La Familia. The High School Journal, 88(2), 32-42. https://doi. org/10.1353/hsj.2004.0023

Jasis, P. M., \& Ordoñez-Jasis, R. (2012). Latino parent involvement: Examining commitment and empowerment in schools. Urban Education, 47(1), 65-89. https:// doi.org/10.1177/0042085911416013

Johnson, A. (2015). The Community Reviewer Program: An examination of a parent empowerment program in Detroit (Publication No. 3740247) [Doctoral dissertation, Michigan State University]. ProQuest Dissertations \& Theses Global.

Khalifa, M. (2010). Validating social and cultural capital of hyperghettoized at-risk students. Education and Urban Society, 42(5), 620-646. https://doi.org/10.1177/ 0013124510366225

Khalifa, M. (2012). A Re-new-ed paradigm in successful urban school leadership principal as community leader. Educational Administration Quarterly, 48(3), 424467. https://doi.org/10.1177/0013161X11432922

Khalifa, M. A. (2018). Culturally responsive school leadership (Vol. 217). Harvard Education Press.

Lane, T. B., \& Id-Deen, L. (2020). Nurturing the capital within: A qualitative investigation of black women and girls in STEM summer programs. Urban Education, 1-29. https://doi.org/10.1177/0042085920926225.

Lareau, A. (2001). Linking Bourdieu's concept of capital to the broader field: The case of family-school relationships. In B. J. Biddle (Ed.), Social class, poverty, and education: Policy and practice (pp. 77-100). Routledge/Falmer.

Lincoln, Y. S., \& Guba, E. G. (1985). Naturalistic inquiry. Sage Publications.

Marchand, A. D., Vassar, R. R., Diemer, M. A., \& Rowley, S. J. (2019). Integrating race, racism, and critical consciousness in black parents' engagement with schools. Journal of Family Theory \& Review, 11(3), 367-384. https://doi.org/ $10.1111 /$ jftr.12344

Marschall, M. J., \& Shah, P. R. (2020). Linking the process and outcomes of parent involvement policy to the parent involvement gap. Urban Education, 55(5), 699-729. https://doi.org/10.1177/0042085916661386

McDermott, P., \& Rothenberg, J. (2000). Why urban parents resist involvement in their children's elementary education. The Qualitative Report, 5(3), 1-16. https://doi.org/10.46743/2160-3715/2000.1947

Noguera, P. A. (2004). Transforming urban schools through investments in the social capital of parents. In Motion Magazine.

Olivos, E. M. (2019). Community and school collaborations: Tapping into community organizing initiatives and resources. in S. B. Sheldon \& T. A. Turner-Vorbeck (Eds.), The Wiley handbook of family, school, and community relationships in education (9-27). Wiley. 
Orr, M., \& Rogers, J. (2010). Unequal schools, unequal voice: The need for public engagement for public education. In M. Orr \& J. Rogers (Eds.), Public engagement for public education: Joining forces to revitalize democracy and equalize schools (pp. 1-24). Stanford University Press.

Osterling, J. P., \& Garza, A. (2004). Strengthening latino parental involvement forming community-based organizations/school partnership. NABE Journal of Research and Practice, 2(1), 270-284.

Patton, M. Q. (2014). Qualitative research \& evaluation methods: Integrating theory and practice. Sage.

Posey-Maddox, L., \& Haley-Lock, A. (2020). One size does not fit all: Understanding parent engagement in the contexts of work, family, and public schooling. Urban Education, 55(5), 671-698. https://doi.org/10.1177/0042085916660348

Putnam, R. D. (2000). Bowling alone: The collapse and revival of American community. Simon and Schuster.

Rusch, D., Frazier, S. L., \& Atkins, M. (2015). Building capacity within communitybased organizations: New directions for mental health promotion for latino immigrant families in urban poverty. Administration and Policy in Mental Health and Mental Health Services Research, 42(1), 1-5. https://doi.org/10.1007/s10488-0140549-1

Sanders, M. (2009). Collaborating for change: How an urban school district and a community-based organization support and sustain school, family, and community partnerships. Teachers College Record, 111(7), 1693-1712. https://doi.org/ 10.1177/016146810911100703

Shirley, D. (1997). Community organizing for urban school reform. University of Texas Press.

Stake, R. E. (1995). The art of case study research. Sage.

Warren, M. R., \& Mapp, K. L. (2011). A match on dry grass: Community organizing as a catalyst for school reform. Oxford University Press.

Yin, R. (2003). Case study research: Design and methods. Sage.

Yosso, T. J. (2005). Whose culture has capital? A critical race theory discussion of community cultural wealth. Race Ethnicity and Education, 8(1), 69-91. https:// doi.org/10.1080/1361332052000341006

Yosso, T. J. (2006). Critical race counterstories along the chicana/chicano educational pipeline. Routledge.

\section{Author Biographies}

Elizabeth Gil, Ph.D. is an assistant professor and School Based Leadership Master's Program Coordinator in the Division of Educational Leadership, Administration, and Policy at Fordham University's Graduate School of Education. Dr. Gil's research interests include understanding the experiences of diverse families in schools, leadership and teaching for serving culturally and linguistically diverse student populations, and community engaged scholarship. Dr. Gil's publications include various peer-reviewed articles in Journal of School Leadership, International Journal of Leadership in Education, and International Journal of Mentoring and Coaching in Education. 
Ashley Johnson, Ph.D. is a Program Officer at The Kresge Foundation where she supports the Education Program which funds student-focused postsecondary access and success efforts that remove barriers to postsecondary degrees for traditionally marginalized populations. Before joining the foundation in 2021, Dr. Johnson served as the founding Executive Director of Detroit College Access Network (DCAN) and the Director of the Detroit Promise, where she led Detroit's citywide college access network and worked to create equitable pathways for postsecondary access and success on behalf of Detroit students and families. 